\title{
Thromboxane B-2 in the plasma and amniotic fluid of late pregnant and periparturient sheep
}

\author{
M. D. Mitchell, B. R. Hicks and J. S. Robinson \\ Nuffield Department of Obstetrics and Gynaecology, University of Oxford, \\ John Radcliffe Hospital, Headington, Oxford, OX3 9DU, U.K.
}

\begin{abstract}
Summary. The concentration of thromboxane (TX) B-2 was similar in plasma from all sources but was significantly greater $(P<0.01)$ in amniotic fluid. Fetal hypophysectomy was without effect on maternal or fetal levels of TXB-2 $(P>0 \cdot 1)$. Neither normal parturition at term nor prematurely induced delivery was associated with any significant trend in TXB-2 levels. During late pregnancy (105-145 days of gestation) the concentrations of TXB-2 and 13, 14-dihydro-15-keto-prostaglandin F (PGFM) in maternal and fetal plasma were significantly correlated $(P<0.001)$. There was, however, no correlation between TXB-2 and PGFM levels in samples taken during the $36 \mathrm{~h}$ before delivery. These data suggest that thromboxanes play little part in the mechanism of parturition in sheep.
\end{abstract}

\section{Introduction}

Prostaglandin (PG) F has been implicated in the mechanism of parturition in the sheep (Liggins \& Grieves, 1971; Thorburn, Nicol, Bassett, Shutt \& Cox, 1972). It now appears possible that PGE may also play an important role during parturition in this species (Challis, Dilley, Robinson \& Thorburn, 1976; Louis, Challis, Robinson \& Thorburn, 1976). The recent discoveries of two other highly potent metabolic products of prostaglandin endoperoxides, i.e. thromboxane (TX) A-2 (Hamberg, Svensson \& Samuelsson, 1975) and prostacyclin (PGI-2) (Moncada, Gryglewski, Bunting \& Vane, 1976), have led to investigation of their possible involvement in ovine parturition. We have developed a radioimmunoassay for TXB-2, the stable metabolite of TXA-2 (Mitchell et al., 1978), and report here its concentrations in plasma and amniotic fluid during late ovine pregnancy, parturition and after fetal hypophysectomy.

\section{Materials and Methods}

Twelve (12) crossbred sheep were used. The day of marking by an intact raddled ram was taken as Day 0 of pregnancy. Fetal, amniotic and maternal catheters were implanted at laparotomy between Days 100 and 125 of gestation by strictly aseptic procedures that have been described previously (Challis et al., 1976; Jones, Kendall, Ritchie, Robinson \& Thorburn, 1978). In 3 animals the fetus was hypophysectomized; the success of the procedure was confirmed by examination of the pituitary fossa and measurements of growth hormone and prolactin in fetal plasma (Jones et al., 1978). Of the remaining 9 animals, 5 gave birth naturally at term and in 4 parturition was induced prematurely by intra-fetal administration of dexamethasone or $\mathrm{ACTH}_{1-24}$ (Synacthen: Ciba Geigy) (Liggins, 1968).

Blood samples were collected into ice-cold tubes containing heparin and centrifuged immediately at $1500 \mathrm{~g}$ and $4^{\circ} \mathrm{C}$; plasma was separated and stored at $-20^{\circ} \mathrm{C}$ until analysis. The 13,14-dihydro-15-keto-prostaglandin F (PGFM) was measured by radioimmunoassay as 
described previously (Mitchell, Flint \& Turnbull, 1976). This assay uses an antiserum supplied by Dr K. T. Kirton (Upjohn Co., U.S.A.) which is highly specific for PGFM except for an $8 \%$ cross-reaction with 15-keto-prostaglandin F-2 $\alpha$. The lower limit of sensitivity was $10 \mathrm{pg} / \mathrm{tube}$ and intra- and inter-assay coefficients of variation during these studies were 8.0 and $12.4 \%$ respectively. TXB-2 was also measured by a specific radioimmunoassay (Mitchell et al., 1978) based on an assay described by Sors et al. (1978). Essential assay details and evaluation were as follows.

The general reagents, methods of extraction, assay and separation technique were by published methodology (Sors, Maclouf, Pradelles \& Dray, 1977). The inclusion of a chromatographic step in the assay was not necessary since measured levels were similar with or without such a procedure (for sheep plasma $t=1, n=6, P>0.05$ by Wilcoxon Signed Rank Test). Good agreement was found between the concentrations measured following extraction of various volumes of plasma $(0.25-3.0 \mathrm{ml})$. Accuracy of the assay was determined by the recovery of standards $(0-100 \mathrm{pg})$ added in triplicate to sheep plasma. Linear regression analysis on recovered standards, corrected for endogenous levels, gave: $y=1.09 x-2 \cdot 24, r=0.97$, where $y$ $=$ amount recovered and $x=$ amount added. Intra- and inter-assay coefficients of variation were 6.3 and $10.0 \%$ respectively. The lower limit of sensitivity of the assay was $2 \mathrm{pg} / \mathrm{tube}$.

Statistical differences were computed by the Mann-Whitney Rank Sum Test (unpaired samples) and the Wilcoxon Signed Rank Test (paired samples) and correlations were assessed by computing the Spearman Rank Correlation Coefficient (Siegel, 1956).

\section{Results}

The data for the normal late pregnant sheep are summarized in Table 1. Jugular venous samples were available from all the sheep studied, but only samples obtained before the start of dexamethasone or Synacthen infusions (and before the onset of labour) were included.

Table 1. Concentrations (mean \pm s.e.m.) of thromboxane B-2 in plasma and amniotic fluid from late pregnant sheep (105-145 days of pregnancy)

\begin{tabular}{lccc}
\hline \multicolumn{1}{c}{$\begin{array}{c}\text { Source of } \\
\text { fluid }\end{array}$} & $\begin{array}{c}\text { No. of } \\
\text { animals }\end{array}$ & $\begin{array}{c}\text { No. of } \\
\text { samples }\end{array}$ & $\begin{array}{c}\text { Conc. of } \\
\text { TXB-2 (pg/ml) }\end{array}$ \\
\hline Maternal jugular vein & 9 & 97 & $196 \pm 9$ \\
Maternal carotid artery & 3 & 31 & $226 \pm 19$ \\
Maternal utero-ovarian vein & 4 & 57 & $214 \pm 14$ \\
Fetal plasma & 5 & 32 & $179 \pm 31$ \\
Amniotic fluid & 2 & 14 & $345 \pm 24$ \\
\hline
\end{tabular}

Table 2. Concentrations (mean \pm s.e.m.) of thromboxane B-2 in plasma from sheep bearing hypophysectomized fetuses (116-171 days of pregnancy)

\begin{tabular}{lccc}
\hline $\begin{array}{c}\text { Source of } \\
\text { fluid }\end{array}$ & $\begin{array}{c}\text { No. of } \\
\text { animals }\end{array}$ & $\begin{array}{c}\text { No. of } \\
\text { samples }\end{array}$ & $\begin{array}{c}\text { Conc. of } \\
\text { TXB-2 (pg/ml) }\end{array}$ \\
\hline Maternal carotid artery & 3 & 45 & $193 \pm 18$ \\
Fetal plasma & 3 & 46 & $170 \pm 13$ \\
\hline
\end{tabular}

To reduce any possible variation due to time and method of sampling only paired samples were used to evaluate statistical differences between TXB-2 levels from different sources. There were no significant differences $(P>0.05)$ between the concentrations of TXB-2 in plasma from any source. Amniotic fluid, however, contained significantly greater concentrations of TXB-2 than did plasma $(P<0.01)$. The maternal and fetal plasma concentrations of TXB-2 in sheep 


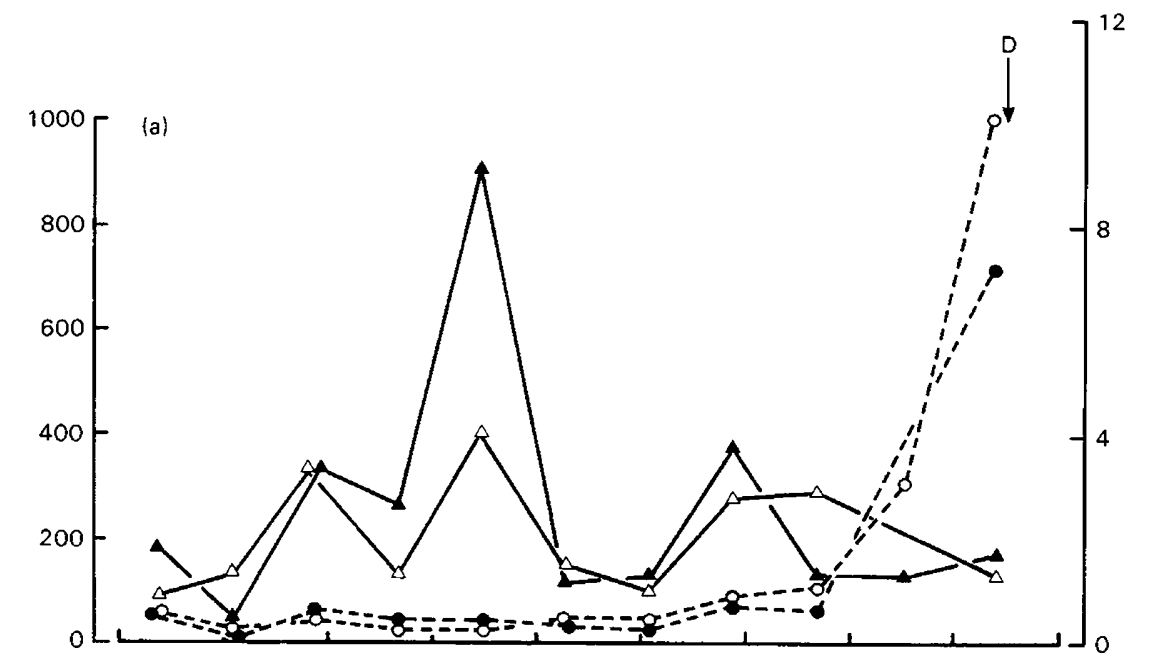

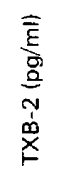

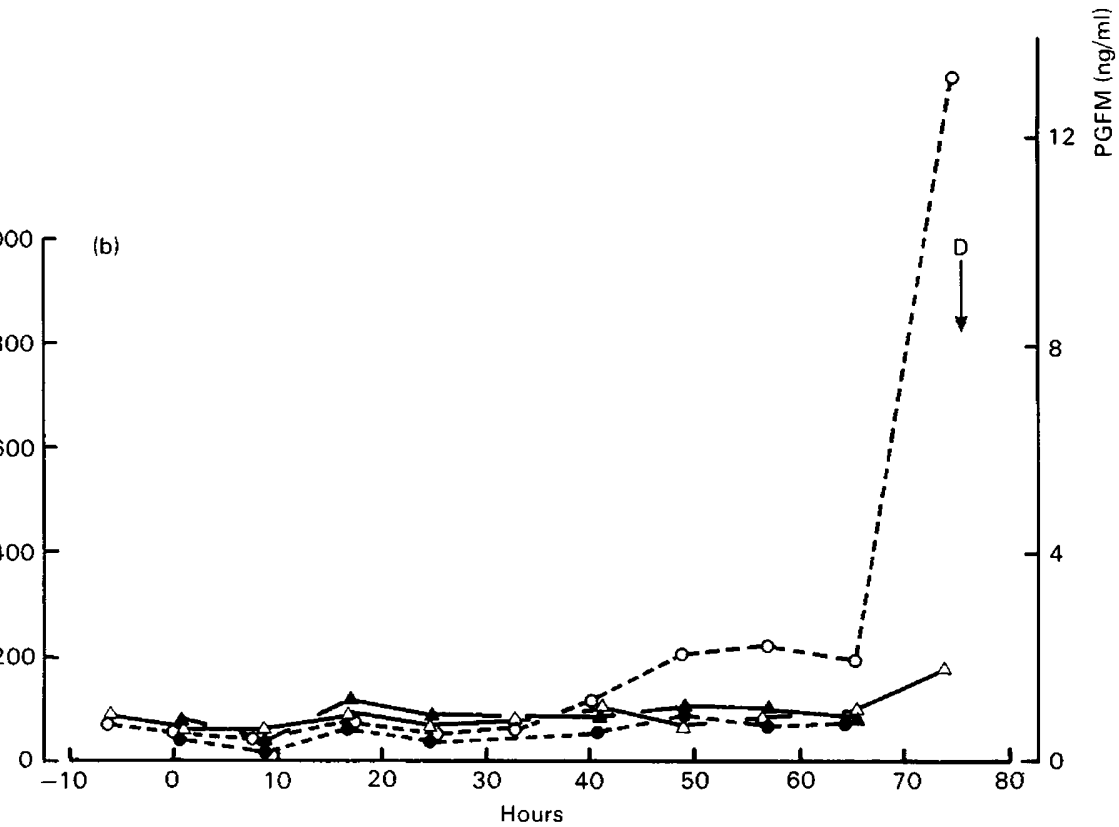

Text-fig. 1. Concentrations of thromboxane B-2 (- - ) and 13,14-dihydro-15-keto-prostaglandin $\mathrm{F}(---)$ in (a) carotid arterial $(\triangle, 0)$ and jugular venous $(\Delta, \boldsymbol{O})$ plasma and (b) uteroovarian venous $(\triangle, 0)$ and fetal $(\Delta, \boldsymbol{O})$ plasma before and during intrafetal infusion of Synacthen $\left(\mathrm{ACTH}_{1-24}, 10 \mu \mathrm{g} / \mathrm{h}\right) .0=$ the start of the infusion: $\mathrm{D}=$ delivery.

bearing hypophysectomized fetuses (Table 2) were similar to those found in control sheep $(P>$ $0 \cdot 1)$, and there was no significant difference $(P>0 \cdot 1)$ between fetal and maternal levels.

Blood samples were obtained more frequently from sheep during the induction of delivery to allow assessment of possible trends in TXB-2 levels during this period. There were no consistent trends in the plasma concentration of TXB-2 during parturition although utero-ovarian venous levels increased slowly but noticeably during the induction of labour in 2 animals. These findings are exemplified by the data from one of these animals shown in Text-fig. 1 . This ewe gave birth to a live-born lamb $75 \mathrm{~h}$ after the start of an intrafetal infusion of Synacthen $\left(\mathrm{ACTH}_{1-24}, 10 \mu \mathrm{g} / \mathrm{h}\right)$. 
Table 3. Correlations between the plasma concentrations of thromboxane B-2 and 13,14-dihydro-15-keto-prostaglandin $\mathrm{F}$

\begin{tabular}{lcccc}
\hline $\begin{array}{l}\text { Source of } \\
\text { fluid }\end{array}$ & $\begin{array}{c}\text { No. of } \\
\text { animals }\end{array}$ & $\begin{array}{c}\text { Spearman's } \\
\text { rho }\end{array}$ & $\begin{array}{c}\text { No. of } \\
\text { samples }\end{array}$ & Significance \\
\hline $\begin{array}{l}\text { During late pregnancy } \\
\text { Jugular vein }\end{array}$ & 9 & 0.562 & 41 & $P<0.001$ \\
$\begin{array}{l}\text { Utero-ovarian vein } \\
\text { Fetal plasma }\end{array}$ & 4 & 0.863 & 24 & $P<0.001$ \\
& 5 & 0.800 & 20 & $P<0.001$ \\
$\begin{array}{l}\text { During the 36 h before delivery } \\
\text { Jugular vein }\end{array}$ & 5 & 0.096 & 43 & $P>0.1$ \\
$\begin{array}{l}\text { Utero-ovarian vein } \\
\text { Fetal plasma }\end{array}$ & 4 & 0.136 & 25 & $P>0.1$ \\
& 2 & 0.168 & 16 & $P>0.1$ \\
\hline
\end{tabular}

The concentration of PGFM was also measured in all samples assayed for TXB-2 and a correlation between the two sets of values was examined (Table 3 ). The data were analysed in two groups; one group comprised only samples obtained during late pregnancy before labour and the other group included only samples obtained during the $36 \mathrm{~h}$ before delivery. PGFM and TXB-2 were highly correlated before labour but not during the later stages of parturition.

\section{Discussion}

These results have demonstrated that there is no significant arterio-venous difference for TXB-2 across the uterus or the head. Furthermore, there is no fetal-maternal gradient for TXB-2 and we could demonstrate no distinct trends in TXB-2 concentrations in plasma or amniotic fluid during parturition although amniotic fluid levels were greater than plasma levels. This evaluation of lack of a trend in TXB-2 concentrations with parturition is based primarily on observations during induced parturition because large numbers of samples are thus available at the appropriate time. Although it is likely that a similar lack of trends occurs in normal parturition, this has not been demonstrated unequivocally. Nevertheless, it is difficult to reconcile such findings with any major role for thromboxanes in ovine parturition.

The correlation between TXB-2 and PGFM concentrations during late pregnancy was not surprising considering their common precursors. The lack of correlation between their concentrations in the $36 \mathrm{~h}$ before delivery probably reflects the fact that PGFM levels were rising rapidly during this period whereas TXB-2 levels remained unchanged (Text-fig. 1). It may be inferred that maternal PGF (Liggins \& Grieves, 1971; Thorburn et al., 1972) and fetal PGE (Challis et al., 1976) levels were also raised during the period when TXB-2 levels were unaltered. These observations suggest that the availability of free arachidonic acid is not the rate-limiting step in the control of PG synthesis because it is the common precursor of thromboxanes and prostaglandins. It seems more likely that it is the activities of the enzymes responsible for the conversion of prostaglandin endoperoxides to prostaglandins, thromboxanes and prostacyclin which may ultimately control the concentrations of the latter compounds under physiological conditions. We have put forward this suggestion previously (Mitchell et al., 1978) on the basis of our findings on tissue production and plasma levels of thromboxanes and prostaglandins in man. The discovery of an endogenous factor in blood which inhibits prostaglandin synthesis in man (Saeed et al., 1977) may, however, radically alter our concept of the control of prostaglandin synthesis. Nevertheless, the present data do not suggest a role for thromboxanes in ovine parturition.

We thank Dr K. T. Kirton and Dr J. E. Pike (Upjohn Co., Kalamazoo) for gifts of 
PG antisera and authentic standards of PGFM and TXB-2. Dr F. Dray (Pasteur Institute, Paris) kindly donated the antiserum to TXB-2. We are grateful to Mrs E. J. Kingston for expert technical assistance. M.D.M. acknowledges receipt of the Staines Medical Research Fellowship (Exeter College, Oxford). This work was supported by the M. R. C. (U.K.).

\section{References}

Challis, J.R.G., Dilley, S.R., Robinson, J.S. \& Thorburn, G.D. (1976) Prostaglandins in the circulation of the fetal lamb. Prostaglandins 11, 1041-1052.

Hamberg, M., Svensson, J. \& Samuelsson, B. (1975) Thromboxanes: a new group of biologically active compounds derived from prostaglandin endoperoxides. Proc. natn. Acad. Sci. U.S.A. 72, 2994 2998.

Jones, C.T., Kendall, J.Z., Ritchie, J.W.K., Robinson, J.S. \& Thorburn, G.D. (1978) Adrenocorticotrophin and corticosteroid changes during dexamethasone infusion to intact and synacthen infusion to hypophysectomized foetuses. Acta endocr., Copenh. 87, 203211.

Liggins, G.C. (1968) Premature parturition after infusion of corticotrophin or cortisol into fetal lambs. $J$. Endocr. 42, 323-329.

Liggins, G.C. \& Grieves, S.A. (1971) Possible role for prostaglandin $\mathrm{F}_{2} \alpha$ in parturition in sheep. Nature, Lond. 232, 629-631.

Louis, T.M., Challis, J.R.G., Robinson, J.S. \& Thorburn, G.D. (1976) Rapid increases of foetal corticosteroids after prostaglandin $\mathrm{E}_{2}$. Nature, Lond. 264, 797-799.

Mitchell, M.D., Bibby, J.G., Hicks, B.R., Redman, C.W.G., Anderson, A.B.M. \& Turnbull, A.C. (1978) Thromboxane $\mathbf{B}_{2}$ and human parturition: concentrations in plasma and production in vitro. J. Endocr. 78, 435-441.
Mitchell, M.D., Flint, A.P.F. \& Turnbull, A.C. (1976) Plasma concentrations of 13,14-dihydro-15-ketoprostaglandin F during pregnancy in sheep. Prostaglandins 11, 319-329.

Moncada, S., Gryglewski, R., Bunting, S. \& Vane, J.R. (1976) An enzyme isolated from arteries transforms prostaglandin endoperoxides to an unstable substance that inhibits platelet aggregation. Nature, Lond. 263, 663-665.

Saeed, S.A., McDonald-Gibson, W.J., Cuthbert, J., Copas, J.L., Schneider, C., Gardiner, P.J., Butt, N.M. \& Collier H.O.J. (1977) Endogenous inhibitor of prostaglandin synthetase. Nature, Lond. 270, 32-36.

Siegel, S. (1956) Nonparametric Statistics for the Behavioral Sciences. McGraw-Hill, New York.

Sors, H., Maclouf, J., Pradelles, P. \& Dray, F. (1977) The use of iodinated tracers for a sensitive radioimmunoassay of 13,14-dihydro-15-keto prostaglandin F. Biochim. biophys. Acta 486, 553-564.

Sors, H., Maclouf, J., Pradelles, P., Rigaud, M., Bernard, P. \& Dray, F. (1978) Analytical methods for thromboxane $\mathbf{B}_{2}$ measurement: validation of radioimmunoassay by gas liquid chromatography-mass spectrometry. Prostaglandins 16, 277-290.

Thorburn, G.D., Nicol, D.H., Bassett, J.M., Shutt, D.A. \& Cox, R.I. (1972) Parturition in the goat and sheep: changes in corticosteroids, progesterone, oestrogens and prostaglandin F. J. Reprod. Fert., Suppl. 16, 6184. 